\title{
BRAIN MUSIC: INTRODUCING RESEARCH THINKING TO THE SECONDARY EDUCATION CURRICULUM
}

\author{
Athina Malliou, Spyretta Vaxevanidi, \& Lefkothea-Vasiliki Andreou \\ Department of Biological Applications and Technologies, University of Ioannina (Greece)
}

\begin{abstract}
Streaming music services are becoming increasingly popular especially among the younger population. Interestingly, this topic is somewhat connected to neurobiology as recent PET and fMRI studies have shown. The present lesson plan aims to educate about the impact of music on the human brain and how it can possibly affect mental health. More specifically, the neural basis for the impact of music on emotions is described along with a peak on brain data and the function of the tools used for imaging the living brain. Students are directed to platforms such as Spotify and YouTube to engage in activities that combine leisure and science in a digital medium. They are asked to record their emotion in relation to the music and to later form a hypothesis that explains their data. This Biology lesson is intended for teenagers and young adults and is designed to promote technology literacy, student participation and initiative. Importantly, the generation of new research ideas and research thinking are actively encouraged.
\end{abstract}

Keywords: Biology, secondary education, active learning, technology literacy, research culture.

\section{Introduction}

"Music...perception involves the mapping of sound onto meaning (and emotion) ...This processing must include feedback as well as feedforward systems as well as making contact with stored memories and experiences as well as emotional systems" (Baars \& Gage, 2014). In the present study, we teach the impact of music to the human brain and mental health in a series of activities that promote research thinking (Rinatovna, 2017), active learning (Handelsman, Miller, \& Pfund, 2007) and technology literacy (Andreou, 2019).

\section{Methodology}

Subject: Biology - Topic: The impact of music on the human brain. - Age group: teenagers and young adults - Time: 90 minutes.

\subsection{Educational Goals}

Through this teaching approach we aim to: 1) Promote science literacy and technology literacy in secondary education, 2) Encourage students to engage in active learning and critical thinking activities, 3) Promote students' research thinking, 4) Help students develop collaboration skills, 5) Educate students on neuroscience topics, 6) Introduce the concept of mental health, 7) Educate on the importance of emotional and mental health, 8) Encourage students to appreciate listening to music as a leisure activity.

\subsection{Materials}

Video projector, IT (Information Technology) classroom with Internet connection.

\subsection{Procedure}

The present lesson plan spans over two teaching hours. In the first hour we focus on formulating a research hypothesis and researching scholarly literature. In the second hour, students assess their understanding and evaluate the lesson.

2.3.1. $1^{\text {st }}$ Phase: (time: $\left.45 \mathrm{~min}\right) .1^{\text {st }}$ micro-activity (time: $35 \mathrm{~min}$ ). Educating on the impact of music on the human brain and its link to mental health. Students form a research hypothesis:

1. Students are requested to listen to several music tracks on the platforms Spotify (https://www.spotify.com) and YouTube (https://www.youtube.com/) and to record their emotional responses to the music by filling-in a spreadsheet that is handed out to them. 
2. Once finished, students are instructed to work in teams to compare their results and to produce a short description of their main findings.

3. Following their feedback, the instructor poses the following questions: "Why certain music tracks tend to correlate with the production of certain emotions? Also, how can the disparity of emotional responses between individuals may be accounted for?" Discuss this question with your team and generate a hypothesis. Try to include to your hypothesis your previous knowledge of higher cognitive functions of our brain, e.g. audition (hearing), memory, emotion.

4. At a next step, students are invited to hold a plenary discussion, each team aiming to convince others that their hypothesis is correct.

5. The activity is concluded with a discussion on recent research evidence employing brain imaging techniques that shows a link between music and strong emotional responses (Chen et al., 2017) and how these may differ based on stored memories or depression (Lepping et al., 2016).

$2^{\text {nd }}$ micro-activity (time: $10 \mathrm{~min}$ ). Introducing the concept of mental health and reviewing technological advances that aim to address mental health disorders. Students research science literature:

1. Introduce students to a mobile health (mHealth) Android application (Psychologist in a Pocket; PiaP) that monitors mobile users' electronically inputted text and screens it for depression symptoms (Cheng et al., 2016).

2. Request that students use the Google Scholar search engine (https://scholar.google.com/) to research for relevant literature, namely scholarly science papers.

3. Students will prepare a Canva presentation (https://www.canva.com/) and give a 3 min talk in class in the following week on their findings, limited to their top 3 papers of interest. Key points, major challenges and cutting-edge technological methodologies should be included in their presentation.

2.3.2. $2^{\text {nd }}$ Phase: (time: $45 \mathrm{~min}$ ). $3^{\text {rd }}$ micro-activity (time: $35 \mathrm{~min}$ ). This is an activity that prompts students to collaborate in order to solve an "escape room" type of challenge. The activity is designed to promote and assess students' understanding of the biology of the human brain (Nicholson, 2018).

1. Warmer: Introduce students to a fictional storyline, where they need to solve puzzles in order to escape from a "room" and get a reward (e.g. first team out may choose next class excursion destination). To complete their mission in this educational game, they will have to answer questions correctly about the human brain and the impact of music on brain activity.

2. Educational Escape Room Activity:

a. Randomly allocate students to groups of 4-5 people with the help of a Random Sequence Generator (https://www.random.org/sequences) based on their Student ID number.

b. The escape room puzzles comprise of 5 types of exercises (multiple choice, true/false, matching, gap filling and a crossword). Upon providing successful answers students will obtain 5 different "keys" so that they may "escape" the room.

c. Puzzles and "locks" will be accessible to students via Google Forms (https://www.google.com/forms/about/).

d. Escape room study material will also be available on the class shared Google Drive folder (https://www.google.com/drive/).

2.3.3. Evaluation (time: 10 min). The following steps are employed to assess students' comprehension:

1. Reflect on new knowledge acquired on cognitive neuroscience and hold a plenary discussion on students' prior perception of the issues introduced here and whether this has shifted as a result of the lesson.

2. Before leaving class, check students' reception of the lesson by asking them to provide short answers on an Exit Ticket (Andreou, 2019).

\section{Conclusions}

The need for innovations in teaching Biology has been well-described in recent reviews of educational research (Wood, 2009). In this study, we aim to activate prior science knowledge (Andreou, Aletra, Athanasopoulou, \& Psarropoulou, 2018) and promote active learning (Handelsman, Miller, $\&$ Pfund, 2007). Importantly, in the present paper, we introduce and encourage the incorporation of research thinking in biology teaching in secondary education. In a series of activities, students engage in data collection and interpretation, scholarly literature, and science communication. By means of using digital media familiar to students (Schriewer \& Bulaj, 2016), we activate prior science knowledge and promote motivation for learning. An investigation of the student experience and the learning outcomes as compared to traditional lecturing will help shed more light to the degree of the effectiveness of such an educational approach. 


\section{References}

Andreou, L.-V. (2019). Remembrance Day: A Micro-Scenario-Based Teaching of English as a Foreign Language Employing Micro-Activities in a Digital Environment. INTED2019 Proceedings. doi: 10.21125/inted.2019.1833

Andreou, L.-V., Aletra, V., Athanasopoulou, G., \& Psarropoulou, C. (2018). Good Practices in Teaching English for Scientific Purposes to Biology Students in Higher Education. INTED2018 Proceedings. doi: 10.21125/inted.2018.1679

Baars, B. J., \& Gage, N. M. )2014). Cognition, brain, and consciousness: introduction to cognitive neuroscience. Amsterdam: Elsevier/Academic Press.

Chen, Q., Zhang, Y., Hou, H., Du, F., Wu, S., Chen, L., \& Tian, M. (2017). Neural correlates of the popular music phenomenon: evidence from functional MRI and PET imaging. European Journal of Nuclear Medicine and Molecular Imaging, 44(6), 1033-1041. doi: 10.1007/s00259-017-3614-7

Cheng, P. G. F., Ramos, R. M., Bitsch, J. Á., Jonas, S. M., Ix, T., See, P. L. Q., \& Wehrle, K. (2016). Psychologist in a Pocket: Lexicon Development and Content Validation of a Mobile-Based App for Depression Screening. JMIR MHealth and UHealth, 4(3). doi: 10.2196/mhealth.5284

Handelsman, J., Miller, S., \& Pfund, C. (2007). Scientific teaching. New York: Freeman.

Lepping, R. J., Atchley, R. A., Chrysikou, E. G., Martin, L. E., Clair, A. A., Ingram, R. E., \& Savage, C. R. (2016). Correction: Neural Processing of Emotional Musical and Nonmusical Stimuli in Depression. Plos One, 11(9). doi: 10.1371/journal.pone.0163631

Nicholson, S. (2018). Creating engaging escape rooms for the classroom. Childhood Education, 94(1), 44-49.

Rinatovna, K. L. (2017). Psychological and Pedagogical Foundations of Undergraduates' Research Thinking Development Process. Procedia - Social and Behavioral Sciences, 237, 1405-1411. doi: 10.1016/j.sbspro.2017.02.205

Schriewer, K., \& Bulaj, G. (2016). Music Streaming Services as Adjunct Therapies for Depression, Anxiety, and Bipolar Symptoms: Convergence of Digital Technologies, Mobile Apps, Emotions, and Global Mental Health. Frontiers in Public Health, 4. doi: 10.3389/fpubh.2016.00217

Wood, W. B. (2009). Innovations in teaching undergraduate biology and why we need them. Annual Review of Cell and Developmental, 25, 93-112. 